\title{
Riwayat Pengobatan dan Komorbid Diabetes Mellitus Berhubungan Dengan Kejadian Tuberkulosis Resisten Obat
}

\section{Medication History and Comorbid Diabetes Mellitus Associated with the Incidence of Tuberculosis Drug Resistant}

\author{
Dafrosia Darmi Manggasa*1, Dewi Nurviana Suharto ${ }^{1}$ \\ ${ }^{1}$ Poltekkes Kemenkes Palu, Indonesia \\ (email : dafrosiamanggasa@yahoo.com)
}

\begin{abstract}
ABSTRAK
Tujuan penelitian untuk menganalisis hubungan antara riwayat pengobatan Tuberkulosis (TB) sebelumnya dan komorbid Diabetes Mellitus (DM) dengan kejadian Tuberkulosis Resisten Obat (TB RO) di Kabupaten Poso. Metode penelitian yaitu observasional analitik dengan desain studi case control. Populasi yaitu seluruh pasien penderita TB di Kabupaten Poso. Sampel yaitu 32 pasien TB RO sebagai kelompok kasus dan 32 penderita TB Sensitifi Obat (TB SO) sebagai kelompok kontrol. Pengambilan data dengan mengidentifikasi data Sistem Informasi Tuberkulosis (SITB). Analisis statistik menggunakan uji chi Square. Hasil penelitian menunjukkan pasien TB yang pernah menjalani pengobatan sebelumnya yaitu TB RO sebesar $65,5 \%$ dan TB SO sebesar 18,8\%, dengan nilai $p=0,000$, pasien TB yang tidak teratur minum obat yaitu TB RO sebesar 71,9\% dan TB SO sebesar 15,6\% dengan nilai $p=0,000$, pasien TB yang menderita komorbid DM yaitu TB RO sebesar 31,3\% dan TB SO sebesar $6,3 \%$ dengan nilai $\mathrm{p}=0,025$. Kesimpulan terdapat hubungan antara riwayat pengobatan sebelumnya dan adanya komorbid DM dengan kejadian TB RO pada pasien TB di Kabupaten Poso. Saran agar fasilitas pelayanan kesehatan meningkatkan manajemen program layanan TB untuk menjamin keteraturan minum obat sehingga mencegah terjadinya TB RO.
\end{abstract}

Kata kunci : Riwayat Pengobatan, Diabetes Mellitus, Tuberkulosis, Resisten Obat

\section{ABSTRACT}

The aim of the study was to analyze the relationship between previous history of tuberculosis (TB) treatment and comorbid Diabetes Mellitus (DM) with the incidence of drug-resistant tuberculosis (ROTB) in Poso Regency. The research method is analytic observational with case control study design. The population is all patients with TB in Poso District. The samples were 32 patients with TB RO as the case group and 32 patients with Drug Sensitive TB (TB SO) as the control group. Data collection by identifying the Tuberculosis Information System (SITB) data. Statistical analysis using chi square test. The results showed that TB patients who had undergone previous treatment, namely TB RO by $65.5 \%$ and TB SO by $18.8 \%$, with a $p$ value $=0.000, T B$ patients who did not regularly take drugs, namely $T B$ $R O$ by $71.9 \%$ and $T B S O$ was $15.6 \%$ with $p$ value $=0.000 \mathrm{~TB}$ patients suffering from comorbid DM, namely TB RO by $31.3 \%$ and TB SO by $6.3 \%$ with $p$ value $=0.025$. The conclusion there is a relationship between previous treatment history and the presence of comorbid DM with the incidence of ROTB in $T B$ patients in Poso Regency. Suggestions that health care facilities improve TB service program management to ensure regularity of taking medication so as to prevent the occurrence of TB RO.

Keywords : Medication History, Diabetes Mellitus, Tuberculosis, Drug Resistance

https://doi.org/10.33860/jik.v15i4.659

(C) 2021 by the authors. Submitted for possible open access publication under the terms and conditions of the Creative

Commons Attribution (CC BY SA) license (https://creativecommons.org/licenses/by-sa/4.0/). 


\section{PENDAHULUAN}

Salah satu penyakit yang masih menjadi ancaman kesehatan bagi masyarakat di Indonesia yaitu penyakit Tuberkulosis (TB). Pada tahun 2019 kasus TB di Indonesia diperkirakan sebanyak 845.000 kasus dengan insidensi 312 per 100.000 . Indonesia menjadi negara dengan jumlah kasus terbesar kedua di dunia setelah India ${ }^{1}$. Peningkatan kasus tuberkulosis juga diikuti dengan penemuan kasus Tuberkulosis Resisten Obat ganda (TB RO). Kasus TB RO yang meningkat menambah beban dalam penanganan penyakit TB. TB dengan Resisten Obat adalah suatu kondisi dimana Obat Anti Tuberkulosis (OAT) sudah tidak mampu lagi membunuh bakteri TB. TB RO apabila mikobakterium $\mathrm{TB}$ resisten terhadap minimal dua OAT lini pertama, yaitu terhadap rifampisin dan INH dengan atau tanpa OAT lainnya. TB RO merupakan salah satu tantangan dalam program pengendalian $\mathrm{TB}$, hal ini disebabkan karena tingginya angka kegagalan pengobatan, sulitnya penegakan diagnosis dan kematian. Identifikasi faktor atau kondisi yang berhubungan dengan kejadian TB RO sangat penting sebagai dasar dalam pengembangan program strategi pencegahan dan pengendalian penyakit TB.

Kasus baru TB RO diperkirakan terdapat 490.000 dan tambahan 110.000 orang dengan TB rifampisin (RR-TB) pada tahun 2016 yang juga baru memenuhi syarat untuk pengobatan TB RO. Negara penyumbang $47 \%$ kasus TB RO yaitu India, China dan Rusia. Indonesia merupakan negara terbanyak ke -4 dari 5 negara penyumbang kasus TB Resisten Obat terbanyak setelah India, China, dan Rusia dan Nigeria menempati urutan ke lima setelah Indonesia ${ }^{2}$. Jumlah kasus TB RO di Kabupaten Poso yang terdiagnosis dari tahun 2015 s/d 2020 sebanyak 32 orang. TB RO terdiagnosis melalui pemeriksaan Tes Cepat Molekuler (TCM) yaitu resisten terhadap rifampisin dan isoniazid dan resistensi pada obat anti tuberkulosis (OAT) lini 1 lainnya sementara jumlah penderita tuberkulosis yang ditemukan pada tahun 2020 diKabupaten Poso sebanyak 45 orang.

Pengobatan tuberkulosis terdiri atas tahan intesif selama 2 bulan dan tahap lanjutan selama 4 bulan yang harus lakukan secara rutin. Kemungkinan resistensi bakteri tuberkulosis terhadap OAT atau Multi Drug Resistance (MDR) dapat terjadi apabila pengobatan terputus atau tidak sesuai dengan standar ${ }^{3}$. Banyaknya kasus TB RO melibatkan faktorfaktor yang terkait. Penelitian menunjukkan bahwa ketidakpatuhan minum obat serta keteraturan obat yang rendah pada pengobatan TB sebelumnya mempengaruhi terjadinya TB $\mathrm{MDR}^{4}$. Riwayat pengobatan TB sebelumnya paling dominan berhubungan dengan kejadian MDR. Riwayat pengobatan TB gagal dan putus berobat merupakan faktor terjadinya TB MDR $^{5}$. Hal yang sama juga dibuktikan dengan penelitian lain yaitu riwayat pengobatan TB berhubungan dengan kejadian MDR $\mathrm{TB}^{6}$. Pada kelompok kasus yang memiliki riwayat pengobatan tuberkulosis gagal atau putus berobat sebelumnya lebih dominan yaitu $73,3 \%$ terjadi TB MDR ${ }^{7}$.

Penyebab terjadinya resistensi obat pada pasien TB diantaranya dipengaruhi oleh faktor petugas kesehatan, pasien dan program pengendalian TB. Pada sisi pasien salah satunya adalah gangguan penyerapan obat akibat menderita komorbid seperti Diabetes Mellitus (DM). Penderita TB dengan komorbid seperti koinfeksi TB-HIV dan Diabetes Mellitus (DM) merupakan salah satu faktor yang menyebabkan TB MDR. Peneltiian menunjukkan ada beberapa faktor lain yang dapat menyebabkan MDR-TB termasuk diantaranya pasien TB yang menderita komorbid seperti $\mathrm{DM}^{8}$

Tingginya angka tuberkulosis di Kabupaten Poso dan juga terus ditemukannya kasus TB Resisten Obat sehingga peneliti tertarik untuk melakukan penelitian yang bertujuan untuk menganalisis hubungan riwayat pengobatan OAT sebelumnya dan adanya komorbid DM dengan kejadian TB resisten obat.

\section{METODE PENELITIAN}

Jenis penelitian yang digunakan adalah penelitian observasional dengan desain studi case control. Penelitian dilakukan dengan cara observasi retrospektif dengan mengidentifikasi data Sistem Infomasi Tuberkulosis (SITB). Data penderita TB di Kabupaten Poso di akses melalui aplikasi SITB oleh admin Kabupaten, kemudian dilakukan identifikasi terhadap riwayat pengobatan sebelumya dan adanya penyakit penyerta yaitu DM yang diderita oleh pasien. Sampel dalam penelitian ini adalah penderita TB di Kabupaten Poso. Jumlah sampel sebanyak 64 orang yang tediri atas 32 responden kasus yaitu penderita TB RO dan 32 
reponden kontrol yaitu penderita TB SO. Data dianalisis menggunakan uji chi square..

\section{HASIL}

Tabel 1 menunjukkan bahwa berdasarkan umur pada reponden kasus yaitu penderita TB RO berada pada rentang usia 16-30 tahun, 3145 tahun dan 46-60 tahun masing-masing sebesar $(31,3 \%)$ dan $\geq 61$ tahun $(6,1 \%)$. Pada reponden kontrol yaitu pasien TB SO berada pada rentang usia $16-30$ tahun $(28,1 \%), 31-45$ tahun $(34,4 \%), 46-60$ tahun $(28,1 \%)$ dan $\geq 61$ tahun $(9,4 \%)$. Pasien dengan TB RO terbanyak laki-laki $(53,1 \%)$ begitu juga dengan TB SO terbanyak laki-laki $(68,8 \%)$. Pasien TB RO terbanyak bekerja disektor swasta $(25 \%)$ dan terendah yaitu pelajar/mahasiswa $(9,4 \%)$. Pada pasien TB SO terbanyak bekerja sebagai petani, buruh/nelayan $(43,8 \%)$ dan terendah bekerja disektor swasta $(3,1 \%)$.

Tabel 1. Karakteristik Responden Berdasarkan Umur, Jenis Kelamin dan Pekerjaan

\begin{tabular}{|c|c|c|c|c|}
\hline \multirow[t]{3}{*}{ Karakteristik } & \multicolumn{4}{|c|}{ Status TB MDR } \\
\hline & \multicolumn{2}{|c|}{ TB RO } & \multicolumn{2}{|c|}{ TB SO } \\
\hline & $\mathrm{n}$ & $\%$ & $\mathrm{n}$ & $\%$ \\
\hline \multicolumn{5}{|l|}{ Umur } \\
\hline 16-30 Tahun & 10 & 31,3 & 8 & 28,1 \\
\hline 31-45 Tahun & 10 & 31,3 & 12 & 34,4 \\
\hline 46-60 Tahun & 10 & 31,3 & 8 & 28,1 \\
\hline$\geq 61$ tahun & 2 & 6,1 & 4 & 9,4 \\
\hline \multicolumn{5}{|l|}{ Jenis Kelamin } \\
\hline Laki-laki & 17 & 53,1 & 22 & 68,8 \\
\hline Perempuan & 15 & 46,9 & 10 & 31,2 \\
\hline \multicolumn{5}{|l|}{ Pekerjaan } \\
\hline PNS, TNI/Polri & 7 & 21,9 & 7 & 21,9 \\
\hline Pensiunan & 1 & 3,1 & 0 & 0 \\
\hline Petani/nelayan & 6 & 18,8 & 14 & 43,8 \\
\hline IRT & 7 & 21,9 & 6 & 18,8 \\
\hline Swasta/wiraswasta & 8 & 25 & 1 & 3,1 \\
\hline Pelajar/mahasiswa & 3 & 9,4 & 4 & 12,5 \\
\hline Total & 32 & 100 & 32 & 100 \\
\hline
\end{tabular}

Tabel 2 Hubungan Riwayat Pengobatan sebelumnya dengan Kejadian TB RO di Kabupaten Poso

\begin{tabular}{|c|c|c|c|c|c|c|}
\hline \multirow{3}{*}{$\begin{array}{c}\text { Riwayat Pengobatan } \\
\text { Sebelumnya }\end{array}$} & \multicolumn{4}{|c|}{ Status TB MDR } & \multirow[t]{3}{*}{$\mathbf{p}$} & \multirow[t]{3}{*}{ OR } \\
\hline & \multicolumn{2}{|c|}{ TB RO } & \multicolumn{2}{|c|}{ TB SO } & & \\
\hline & $\mathrm{n}$ & $\%$ & $\mathrm{n}$ & $\%$ & & \\
\hline Pernah pengobatan OAT & 21 & 65,6 & 6 & 18,8 & 0,000 & 8,273 \\
\hline Baru & 11 & 34,4 & 26 & 81,2 & & \\
\hline Total & 32 & 100 & 32 & 100 & & \\
\hline
\end{tabular}

Tabel 3 Hubungan Komorbid Diabetes Mellitus dengan Kejadian TB RO di Kabupaten Poso

\begin{tabular}{|c|c|c|c|c|c|c|}
\hline \multirow[t]{3}{*}{ Komorbid DM } & \multicolumn{4}{|c|}{ Status TB MDR } & \multirow{3}{*}{$\mathbf{p}$} & \multirow{3}{*}{ OR } \\
\hline & \multicolumn{2}{|c|}{ TB RO } & \multicolumn{2}{|c|}{ TB SO } & & \\
\hline & $\mathrm{n}$ & $\%$ & $\mathrm{n}$ & $\%$ & & \\
\hline Ada DM & 10 & 31,3 & 2 & 6,3 & 0,025 & 6,818 \\
\hline Tidak ada DM & 22 & 68,8 & 30 & 93,7 & & \\
\hline Total & 32 & 100 & 32 & 100 & & \\
\hline
\end{tabular}

Tabel 2 menunjukkan bahwa pada pasien TB RO terbanyak pernah menjalani pengobatan OAT sebelumnya yaitu sebanyak 21 responden $(65,6 \%)$ dan yang belum pernah menjalani pengobatan sebelumnya atau kasus baru sebanyak 11 responden $(34,4 \%)$. Pada pasien TB SO terbanyak yaitu kasus baru 26 responden $(81,2 \%)$ dan yang pernah menjalani pengobatan OAT sebelumnya sebanyak 6 responden $(18,8 \%)$. Hasil analisis statistik dengn uji chi square diperoleh nilai $\mathrm{p}=0,000$ yang berarti terdapat hubungan antara riwayat pengobatan sebelumnya dengan kejadian TB RO di Kabupaten Poso. Nilai OR sebesar 8,273 
yang berarti riwayat pernah pengobatan OAT sebelumnya memiliki risiko terjadinya TB RO sebesar 8,273 kali dibanding yang belum pernah pengobatan sebelumnya.

Tabel 3 menunjukkan pada pasien TB RO terbanyak tidak terdapat komorbid yaitu DM yaitu sebanyak 22 responden $(68,8 \%)$ dan yang menderita DM sebanyak 10 responden $(31,3 \%)$. Pada pasien TB SO terbanyak tidak ada DM yaitu sebanyak 30 responden $(93,7 \%)$ dan yang ada DM sebanyak 2 responden $(6,3 \%)$. Hasil analiss statistik dengan uji chi square diperoleh nilai $p=0,025$ yang berarti ada hubungan antara komorbid DM dengan kejadian TB RO di Kabuapten Poso. Nilai OR sebesar 6,818 yang berarti pasien dengan komorbid DM beresiko terhadap kejadian TB RO sebesar 6,818 dibanding dengan pasien yang tidak memiliki komorbid DM

\section{PEMBAHASAN}

TB-MDR merupakan suatu komplikasi dimana terjadi proses resistensi oleh minimal satu jenis obat yaitu rifampisin dan isoniazid ${ }^{9}$. Pada pasien TB yang masih sensitif obat dapat terjadi resistensi obat akibat penggunaan antibiotik yang tidak tepat seperti ketidaktepatan regimen, dosis obat, dan lama pengobatan serta kegagalan memotivasi pasien untuk menyelesaikan program pengobatan ${ }^{10}$.

Hasil penelitian ini menunjukkan bahwa terdapat hubungan antara riwayat pengobatan sebelumnya dengan kejadian TB RO. Kejadian TB RO terbanyak pada pasien dengan riwayat pernah pengobatan OAT sebelumnya. Pengobatan sebelumnya yang gagal, putus, kambuh memiliki risiko yang lebih besar menjadi TB RO. Pasien yang pernah menelan OAT dengan tatalaksana yang tidak tepat menimbulkan kekebalan kuman TB terhadap OAT. Terdapat pasien dengan TB RO namun belum pernah menjalani pengobatan OAT sebelumnya atau kasus baru. Terjadinya TB RO pada pasien tersebut kemungkinan adanya riwayat kontak erat sebelumnya dengan penderita TB RO atau pasien tidak jujur dalam memberikan informasi terkait pengobatan sebelumnya. Pada pasien Tuberkulosis dengan Sensitif Obat (TB SO) terbanyak merupakan kasus baru, namun terdapat pasien TB SO dengan riwayat pernah pengobatan OAT sebelumnya. Pasien telah menyelesaikan pengobatan namun pasien kembali terdiagnosis TB dipengaruhi oleh beberapa faktor seperti daya tahan tubuh yang menurun, gizi yang kurang baik, dan kontak dengan penderita TB.

Pengobatan terdahulu dan dosis obat yang tidak tepat juga pasien yang menderita DM merupakan faktor yang berpengaruh terhadap terjadinya TB RO. Faktor dokter, pasien, obat, dan sistem pelayanan kesehatan merupakan faktor risiko TB-MDR ${ }^{9}$. Penderita TB dengan pengobatan sebelumnya yang tidak adekuat berisiko mengalami resistensi OAT sebesar 40 kali. Pada sisi pasien yaitu penderita TB yang tidak mematuhi anjuran dokter/petugas kesehatan, tidak teratur menelan OAT, berhenti pengobatan sebelum waktunya, dan gangguan penyerapan obat ${ }^{11}$. Penderita TB yang pernah menjalani pengobatan sebelumnya beresiko terjadinya TB MDR dibandingkan dengan pasien TB kasus baru ${ }^{12}$ Penelitian di RS Moewardi menunjukkan sebagian besar penderita MDR TB memiliki riwayat pengobatan TB kategori 2. Terdapat hubungan signifikan antara pasien riwayat pengobatan kategori 2 sebelumnya dengan MDR TB ${ }^{13}$.

Penelitian lain membuktikan bahwa hasil pengobatan TB berhubungan dengan kejadian TB MDR. Pada responden yang mempunyai hasil pengobatan TB gagal berisiko sebesar 3,5 kali lebih besar untuk terjadinya TB MDR, sementara pada responden dengan riwayat putus berobat $\mathrm{TB}$ mempunyai risiko 5,2 kali lebih besar dibanding dengan responden yang tidak pernah putus berobat ${ }^{14}$. Pengobatan TB yang tidak sesuai dengan standar seperti dosis yang tidak tepat, waktu menelan obat yang berubah-ubah dan berhenti menelan obat merupakan indikasi ketidakteraturan minum obat dan menjadi risiko terjadinya resistensi terhadap OAT lini 1. Ketidakteraturan minum obat pada pengobatan TB sebelumnya dapat disebabkan karena penderita bosan untuk minum obat dalam jangka waktu yang lama dan merasa terbeban, salah menangkap informasi terkait dosis, aturan minum OAT. Berhenti menelan OAT karena adanya efek samping, tidak adanya dukungan keluarga dalam memotivasi, memberikan semangat serta kurangnya perhatian dalam memberikan perawatan apabila terjadi keluhan yang membuat pasien memutuskan berhenti minum obat, motivasi pasien yang kurang dan stigma negatif tentang penyakit TB. Penelitian sebelumnya membuktikan bahwa faktor yang paling dominan yang menyebabkan MDR-TB adalah keteraturan minum obat ${ }^{15}$.

Pasien TB yang tidak taat minum obat 
secara teratur menjadi hambatan mencapai kesembuhan ${ }^{10}$. Peran keluarga penting dalam mengawasi penderita dan selalu mengingatkan untuk minum obat. Apabila pengobatan terputus kuman TB bisa menjadi resisten. Keteraturan minum obat penderita harus diperhatikan untuk mengurangi risiko peningkatan kasus TB MDR ${ }^{16}$. Konseling yang berkualitas dari pengelola program TB sangat penting untuk meningkatkan kepatuhan minum obat sehingga dapat mencegah resistensi OAT ${ }^{17}$

Hasil penelitian ini menunjukkan bahwa terdapat hubungan antara komorbid DM dengan kejadian TB MDR. Adanya penyakit yang diderita oleh pasien TB seperti ko infeksi TB-HIV, DM, gagal ginjal meningkatkan risiko TB RO. Pada penelitian ini tidak ditemukan adanya ko infeksi TB-HIV maupun gagal ginjal, namun terdapat pasien TB RO yang memiliki penyakit penyerta yaitu DM sebesar $31,3 \%$. Pada pasien TB yang menderita DM dan menelan OAT dengan kadar gula darah yang tinggi dapat menyebabkan gangguan absorbsi OAT sehingga efektifitas OAT menurun yang berdampak pada terjadinya resisten OAT. Pasien DM yang mengalami infeksi TB akan sulit dalam pengendalian kadar gula darah. DM meningkatkan risiko TB 1,5 hingga 7,8 kali lipat dibandingkan non $\mathrm{DM}^{18}$. Kondisi penyakit ganda TB-DM dapat menurunkan imunitas tubuh pasien TB sehingga dapat meningkatkan kasus TB RO. Pada pasien DM diduga aktivitas fagositosis dan bakterisid neutropil terganggu, jumlah limfosit $\mathrm{T}$ menurun. Pertahanan host terhadap infeksi mycobacterium menurun ${ }^{19}$.

Hasil penelitiaan ini sejalan dengan penelitian lain yang membuktikan bahwa penyakit penyerta (komorbid) DM berhubungan dengan kejadian TB MDR ${ }^{14}$. DM terbukti meningkatkan risiko TB RO. Penanganan pasien TB yang menderita penyakit DM bertujuan untuk menurunkan angka kematian dan mencegah penularan. Pasien harus mendapatkan pengobatan yang tepat, evaluasi pengobatan dengan ketat (konversi kuman), pengawasan efek samping OAT dan pengontrolan gula ${ }^{20}$.

Keterbatasan penelitian ini yaitu tidak mengambil seluruh penderita TB sebagai sampel, data riwayat pengobatan TB sebelumnya yang tidak diketahui karena penegakan diagnostik yang tidak sesuai kriteria dan sebelum tahun 2020 penegakan diagnostik TB secara mikroskopik belum menggunakan
TCM sehingga tidak semua pasien dapat ditegakkan diagnosis RO. Adapun implikasi hasil penelitian yaitu pengelola program dapat meningkatkan pemantauan pengobatan sesuai dengan petunjuk teknis program TB dan meningkatkan upaya kolaborasi dan integrasi program TB dengan penanggulangan DM. .

\section{KESIMPULAN DAN SARAN}

Hasil penelitian ini membuktikan bahwa terdapat hubungan antara riwayat pengobatan sebelumnya dan adanya komorbid Diabetes Mellitus dengan kejadian tuberkulosis resisten obat di Kabupaten Poso. Saran bagi fasilitas pelayanan kesehatan agar meningkatkan manajemen program layanan $\mathrm{TB}$ untuk menjamin keteraturan minum obat, juga petugas kesehatan dapat melakukan deteksi dini pada kondisi khusus seperti adanya komorbid DM pada penderita TB sehingga mendapatkan penanganan komorbid dengan tepat untuk mencegah terjadinya TB RO.

\section{DAFTAR PUSTAKA}

1. WHO. Global Tuberculosis Report [Internet]. 2020. Available from: https://www.who.int/publications/i/item/97 89240013131

2. World Health Organization (WHO). Global Tuberculosis Report 2017 [Internet]. Geneva; 2017. 1-147 p. Available from: https://www.who.int/tb/publications/global _report/gtbr2017_main_text.pdf

3. Sarwani DS, Nurlaela $\bar{S}$, Zahrotul I. Faktor Risiko Multidrug Resistant Tuberculosis (Mdr-Tb). KESMAS - J Kesehat Masy. 2012;8(1):60-6.

4. Aristiana CD, Wartono M. Faktor-faktor yang mempengaruhi kejadian Multi Drug Resistance Tuberkulosis (MDR-TB). J Biomedika dan Kesehat. 2018;1(1):65-74.

5. Triandari D, Rahayu SR. Kejadian Tuberkulosis Multi Drug Resistant di RSUP dr. Kariadi. HIGEIA (Journal Public Heal Res Dev. 2018;2(2):194-204.

6. Marahatta SB, Kaewkungwal J, Ramasoota P, Singhasivanon P. Risk factors of multidrug resistant tuberculosis in central Nepal: A pilot study. Kathmandu Univ Med J. 2010;8(32):392-7.

7. Aderita NI, Murti B, Suryani N. Risk Factors Affecting Multi-Drug Resistant Tuberculosis in Surakarta and Wonogiri, Central Java, Indonesia. J Epidemiol PublicHealth. 2016;01(02):86-99.

8. Balaji V, Daley P, Anand AA, Sudarsanam T, Michael JS, Sahni RD, et al. Risk factors 
for MDR and XDR-TB in a tertiary referral hospital in India. PLoS One. 2010;5(3):1-6.

9. Syahrezki M. Faktor Risiko Tuberkulosis Multidrug Resistant ( TB-MDR ). J Agromed Unila. 2015;2(4):413-8.

10. Asri SDA. Masalah Tuberkulosis Resisten Obat. Contin Med Educ [Internet]. 2014;41(4):247-9. Available from: http://103.13.36.125/index.php/CDK/article /view/1143/852

11. Nugrahaeni DK, Malik US. Analisis Penyebab Resistensi Obat Anti Tuberkulosis. J Kesehat Masy. 2013;8(2):113-20.

12. Kemenkes RI. Petunjuk Teknis Manajemen Terpadu Pengendalian Tuberkulosisi Resisten Obat. Jakarta: Kementerian Kesehatan Republik Indonesia Direktorat Jenderal Pengendalian Penyakit Dan Penyehatan Lingkungan; 2013. 1-136 p.

13. Reviono, Kusnanto P, Eko V, Pakiding H, Nurwidiasih D. Multidrug Resistant Tuberculosis (MDR-TB): Tinjauan Epidemiologi dan Faktor Risiko Efek Samping Obat Anti Tuberkulosis. Maj Kedokt Bandung. 2014;46(4):189-96.

14. Nurdin N. Analisis faktor-faktor determinan Individu terhadap Tuberculosis Multidrug Resistant (TB MDR) di Provinsi Sumatera Selatan. J Kesehat Komunitas. 2020;6(1):63-7.

15. Muhammad M, Fadli F. Analisis Faktor Penyebab Multi-Drug Resistance (Mdr) Pada Penderita Tuberkulosis. J Publ Kesehat Masy Indones. 2019;6(2):62-7.

16. Mashidayanti A, Nurlely N, Kartinah N. Faktor Risiko Yang Berpengaruh Pada Kejadian Tuberkulosis dengan MultidrugResistant Tuberculosis (MDR-TB) di RSUD Ulin Banjarmasin. J Pharmascience. 2020;7(2):139.

17. Aldina NN, Hermanto RBB, Manggasa DD. Hubungan Konseling dengan Kepatuhan Minum Obat Anti Tuberkulosis Pasien Tuberkulosis di Kabupaten Poso. Madago Nurs J. 2020;1(1):1-6.

18. Niazi AK, Kalra S. Diabetes and tuberculosis: A review of the role of optimal glycemic control. J Diabetes Metab Disord. 2012;11(1):1.

19. Badawi A, Sayegh S, Sallam M, Sadoun E, Al-Thani M, Alam MW asi., et al. The global relationship between the prevalence of diabetes mellitus and incidence of tuberculosis: 2000-2012. Glob J Health Sci. 2015;7(2):183-91.

20. Rosdiana D. Tuberkulosis Paru Resisten Obat dengan Komorbiditas Diabetes Mellitus. J Kesehat Melayu. 2017;1(1):45. 